\title{
Correlation between peak flow and body mass index in obese and non-obese children in Kocaeli, Turkey
}

\author{
*Zuhal Gundogdu ${ }^{\mathrm{a}, \mathrm{b}}$, Nihal Eryilmaz \\ ${ }^{a}$ Kocaeli Metropolitan Municipality Hospital, 41100, Kocaeli, Turkey \\ ${ }^{\text {b }}$ Akademi Hastanesi, 41200, Kocaeli, Turkey
}

Originally submitted 13th April 2010; resubmitted 21st October 2010; revised 17th December 2010; further revision 10th February 2011; accepted 21st March 2011; online 8th July 2011

\begin{abstract}
Aims: To investigate the relationship between body mass index (BMI) and peak expiratory flow (PEF) values in children between the ages of 6 and 14 years.

Methods: Data were collected from 1,439 children during public health screening. Each child was classified on the basis of age- and sexspecific BMI percentile as non-obese or obese (BMI $\geq 95$ th percentile). PEF and BMI were compared among age-sex-BMI percentile groups. Results: PEF values were lower in obese children than in non-obese children. There were also significant differences between girls and boys.

Conclusions: The association of higher BMI with lower PEF may indicate that obesity is an important risk factor for reduced airflow or lung function in children. These findings emphasise the importance of the prevention of obesity in children and adolescents in order to avoid possible future respiratory problems.

(C) 2011 Primary Care Respiratory Society UK. All rights reserved.

Z Gundogdu and N Eryilmaz. Prim Care Respir J 2011; 20(4): 403-406

http://dx.doi.org/10.4104/pcrj.2011.00061
\end{abstract}

Keywords peak expiratory flow, body mass index, lung function, children, obesity

\section{Introduction}

Obesity has become a major public health concern in many parts of the world. In recent years it has reached epidemic proportions among adolescents and children in whom it has become an increasingly important medical problem. Many of the outcomes associated with obesity that were previously considered to be diseases of adults are now also affecting children. ${ }^{1}$ Being overweight or obese increases the risk of many diseases and health conditions, including respiratory problems. ${ }^{2}$

Obesity may also affect lung function. ${ }^{3}$ In adults, pulmonary function abnormalities related to obesity are well-reported complications. The most frequently reported abnormalities are reductions in lung volumes and expiratory flow rates. Similar data in the paediatric population are also reported ${ }^{4}$ but the data are limited, especially in developing countries.

Obese subjects may have impaired lung function, but the mechanism for this is unclear. ${ }^{5}$ Obesity can affect the thorax, diaphragm, and abdominal muscles and - due to increased respiratory effort and impairment of the gas transport system can result in altered respiratory function even if the lungs are normal. As well as having a direct effect on the mechanical behaviour of the respiratory system by altering lung volume, airway calibre or respiratory muscle strength, obesity may also cause impairment of diaphragmatic activity-dependent respiratory function. ${ }^{6-7}$

Reversible and variable airflow limitation are measured with a spirometer (forced expiratory volume in $1 \mathrm{~s}\left(\mathrm{FEV}_{1}\right)$ and forced vital capacity (FVC)) or a peak expiratory flow (PEF) meter in children aged over 5 years. ${ }^{8}$ PEF is the most commonly used method to monitor lung function. ${ }^{9}$ Several kinds of peak flow meters are available and the technique for use is similar for all. ${ }^{8-10}$ PEF measurement is very popular in primary care and is commonly applied as a quick screening method for assessing lung function in the clinic or at the bedside. ${ }^{9}$

Body mass index (BMI) defines and measures adiposity and body composition among adults and children. There is a

\footnotetext{
* Corresponding author: Dr Zuhal Gundogdu, Akademi Hastahanesi, 41200, Kocaeli, Turkey

Tel: +90 5316283285 Fax: +902623031069 E-mail: z.gundo@gmail.com.
} 
general consensus that an age-related BMI should be used, since BMI is significantly associated with body fatness in children and adolescents. It is also known as the Quetelet index and is defined as weight in kilograms divided by the square of the height measurement in metres $\left(\mathrm{kg} / \mathrm{m}^{2}\right)$, and is commonly used as a practical means to assess body fatness. ${ }^{.1}$ For children and adolescents in the clinical setting, BMI percentiles are recommended by the Centres for Disease Control and Prevention, with a BMI equal to or above the 95th percentile suggesting obesity.

Many studies have also demonstrated an association between excess weight or weight gain and pulmonary dysfunction. ${ }^{12}$ Several have considered the association between body composition, fat distribution, and lung function in elderly subjects and the relationship between physical performance and lung function. Most of the studies evaluating the relationship between obesity and respiratory function tests have been carried out in adults. However, a few studies reported in the literature have evaluated the relationship between obesity and respiratory function in children.

The aim of this study was to investigate the effect of obesity on the result of respiratory function tests, to define the relationship between independent variable BMI and dependent variable PEF values in paediatric primary care practices, and to find a possible correlation between these quantities. Throughout the text, BMI should be considered as an independent variable and PEF referred to as a dependent variable in order to avoid repetition.

\section{Methods}

This study was performed using secondary data collected from children aged 6-14 years who were brought in by their parents randomly during weekly public screening days at Kocaeli Metropolitan Municipality Maternity and Children Hospital in Kocaeli, Turkey during 2002. A total of 1,439 children were included in the study.

During the public screening the history of every child was taken by doctors. Children who had already suffered major disorders (cardiac, respiratory, renal, or haematological disorders) and those with asthma symptoms were excluded from the study.

Height (in $\mathrm{cm}$ ) and weight (in $\mathrm{kg}$ ) of the children, with shoes removed and wearing the least possible clothing, were measured during the public screening. The same anthropometric equipment was used for each subject. Age was calculated in (decimal) years for the day of measurement. Standing height was obtained using a stadiometer. The children placed their feet on the base and stood with their backs touching the vertical plate.

Each child was asked to stand up and to hold the peak flow meter without restricting the movement of the marker. The doctor made sure that the marker was at the bottom of the scale for each measurement. The child took a deep breath, put the peak flow meter into his/her mouth, sealed his/her lips around the mouthpiece, and breathed out as hard and fast as possible with the head in a neutral position, neither flexed nor extended. The children were told repeatedly not to put their tongue into the mouthpiece. The marker was returned to zero after every measurement. To avoid the problem of variability due to different technicians and devices, all the tests were performed by one designated person using the same Mini Wright peak flow meter and the PEF ( $L / \mathrm{min})$ was measured by the standard method. ${ }^{8}$ Three measurements were taken and the highest reading was recorded. ${ }^{8}$

$\mathrm{BMI}$ and BMI percentiles (BMI\%) were calculated for each child. The children were divided into two groups - non-obese and obese - depending on their BMI\% values ( $<95$ th percentile or $\geq 95$ th percentile, respectively) using the current Turkish BMI reference values. ${ }^{13}$

The results were analysed to determine if there was any correlation between BMI and PEF values in girls and boys. Statistical evaluation of the results was performed with the SPSS v14 computer program using simple multiple linear regression. All tests were based at the 0.05 level of significance.

\section{Results}

A total of 1,439 children (male/female ratio 763/676) with a mean $\pm S D$ age of $9.67 \pm 2.59$ years were enrolled in the study. The children were divided into non-obese and obese groups according to BMI\% values. The mean PEF values in each $\mathrm{BMI} \%$ group and $\mathrm{BMI}$ values were calculated and compared.

Table 1. Mean age, weight, height, BMI, PEF, BMI in girls and boys, BMI Z-score and M/F of BMI\% groups (non-obese and obese)

\begin{tabular}{lll} 
& $\begin{array}{l}\text { Non obese BMI\% } \\
(\mathrm{n}=1,382)\end{array}$ & $\begin{array}{l}\text { Obese BMI\% } \\
(\mathrm{n}=57)\end{array}$ \\
\hline Age (years) & $9.69 \pm 2.60$ & $9.14 \pm 2.54$ \\
\hline $\mathrm{M} / \mathrm{F}$ & $736 / 646$ & $27 / 30$ \\
\hline Weight $(\mathrm{kg})$ & $32.21 \pm 11.53$ & $43.45 \pm 16.57$ \\
\hline Height $(\mathrm{cm})$ & $133.75 \pm 16.20$ & $133.82 \pm 17.27$ \\
\hline BMI & $17.35 \pm 2.29$ & $23.20 \pm 3.53$ \\
\hline PEF $($ L/min) & $259.83 \pm 82.75$ & $259.47 \pm 71.24$ \\
\hline BMI in girls & $17.32 \pm 2.32(n=646)$ & $24.84 \pm 3.65(n=30)$ \\
\hline BMI in boys & $17.38 \pm 2.27(n=736)$ & $21.53 \pm 2.42(n=27)$ \\
\hline BMI z-scores & $-0.04 \pm 0.65$ & $2.05 \pm 0.37$ \\
\hline PEF in girls & $281.33 \pm 71.52(n=646)$ & $251.28 \pm 78.20(n=30)$ \\
\hline$P E F$ in boys & $267.35 \pm 85.90(n=736)$ & $235.18 \pm 63.75(n=27)$ \\
\hline Values shown are mean $\pm S D$. & \\
\hline M/F=male/female ratio, BMl=body mass index, PEF=peak expiratory flow.
\end{tabular}


The number of children, male/female ratio, mean age, weight, height, BMI and PEF of each group are shown in Table 1. The mean PEF for the obese and non-obese BMI\% groups are also shown in Table 1. The results show that BMI increased and PEF decreased from the non-obese to the obese group; the mean age of the two BMI\% groups was similar.

PEF values for the non-obese and obese groups were compared and the results are shown in Table 2. Simple multiple linear regression was used to include the age factor in a linear Model 1 (Formula $=$ PEF $\sim$ age + height + BMI zscore + BMl z-score $\left.{ }^{2}\right)$. There was a statistically significant decrease in PEF $(p<0.05)$ corresponding to increasing $B M I$ category. PEF values were significantly lower in the obese group than in the non-obese BMI\% group.

Multiple simple linear regression was used, including the age factor, in a linear Model 2 (Formula $=$ PEF $\sim$ age + factor $(\mathrm{BMI}))$. The $\mathrm{p}$ values were found to be statistically significant $(p<0.001)$, indicating that PEF decreases with increasing BMI, as shown in Table 3.

PEF values were adjusted for BMl, also including a height factor in Model 3 as height is a significant factor for PEF to adjust for BMI. PEF showed a graded statistically significant decrease $(p<0.001)$ in obese children (Table 3). After adjustment for age, height, BMI, non-obese and obese $\mathrm{BMI} \%$, the differences in PEF remained statistically significant at $p<0.05$, as shown in Tables 2 and 3 .

PEF was also compared between girls and boys. Simple multiple linear regression was used, including an age factor, in a linear Model 4 (Formula $=$ PEF $\sim$ age + factor (gender)). There were significant differences between girls and boys for PEF $(p<0.001)$, as shown in Table 3. BMI $z$-scores were further adjusted in order to explain the gender difference. The results showed that the difference in height and BMI between boys and girls was significant $(p<0.001)$ in $B M l z$-scores. It was found that the beta value for height was 0.830 and for BMI $z$-score was 0.012 . This also explains the gender-related difference seen in Table 3. When PEF values were compared with $\mathrm{BMI}$ in $\mathrm{BMI} \%$ groups (non-obese and obese) of children, the PEF values were lower in the obese group than in the nonobese group. There was a negative correlation between BMI and PEF in children aged 6-14 years.

\section{Discussion}

Many studies have demonstrated an association between obesity and pulmonary function tests in adults, but there have been only limited studies in children without asthmatic symptoms. In our study, an inverse relationship between respiratory function and obesity was observed in a population of 1,439 children who had no previously known asthma symptoms. The children were grouped as non-obese and obese according to their BMI\%. The effect of childhood obesity on respiratory function and the relation between the BMI, BMI\% and PEF were evaluated. Poulain et al. ${ }^{14}$ reported that increasing BMI is typically associated with a reduction in $\mathrm{FEV}_{1}, \mathrm{FVC}$, total lung capacity,

Table 2. Peak expiratory flow values compared for body mass index (BMI) z-scores in regression including age and height

\begin{tabular}{l|l|l|l|l|l|} 
& $\beta$ & $\mathrm{t}$ & $\mathrm{p}$ value & $95 \% \mathrm{Cl}$ & \multicolumn{1}{l}{ Adjusted $\mathrm{R}^{2}$} \\
\hline Height $(\mathrm{cm})$ & 0.600 & 17.70 & 0.00 & 2.70 to 3.37 & 0.699 \\
\hline Age (years) & 0.258 & 7.52 & 0.00 & 6.03 to 10.29 \\
\hline BMI z-score & -0.043 & 2.53 & 0.01 & 1.06 to 8.27 \\
\hline BMI z-score & -0.013 & -0.795 & 0.04 & -3.72 to 1.57 & \\
\hline
\end{tabular}

Entered variables are $\beta$ (regression coefficient), BMI z-score (body mass index z-score), $\mathrm{Cl}$ (confidence interval)

Table 3. Peak expiratory flow (PEF) values adjusted for body mass index (BMI), height, age, and gender in a linear regression

\begin{tabular}{l|l|l|l|l|l|l|} 
& & $\beta$ & $\mathrm{t}$ & $\mathrm{p}$ value & $95 \% \mathrm{Cl}$ & \multicolumn{1}{c}{ Adjusted $\mathrm{R}^{2}$} \\
\hline \multirow{2}{*}{ Model 2 } & Age & 0.727 & 35.95 & 0.000 & 21.76 to 24.27 & 0.633 \\
\cline { 2 - 7 } & BMl & 0.105 & 5.20 & 0.000 & 2.05 to 4.54 \\
\hline \multirow{2}{*}{ Model 3 } & Height $(\mathrm{cm})$ & 0.788 & 42.33 & 0.000 & 3.80 to 4.17 & 0.690 \\
\cline { 2 - 7 } & BMl & 0.067 & 3.62 & 0.000 & 0.971 to 3.26 \\
\hline \multirow{2}{*}{ Model 4 } & Age & 0.791 & 49.38 & 0.000 & 24.03 to 26.02 & 0.631 \\
\cline { 2 - 6 } & Gender & 0.075 & 4.66 & 0.000 & 7.14 to 17.49 & \\
\hline
\end{tabular}

Entered variables are $\beta$ (regression coefficient), BMI (body mass index), $\mathrm{Cl}$ (confidence intervals) 
functional residual capacity, and respiratory reserve volume. Lazarus et al., ${ }^{15}$ in a sample of 1,235 non-obese subjects aged 18-78 years, showed a decrease in lung function with increasing fat mass and central body fat distribution. Canoy et al..$^{5}$ also reported that negative coefficients were apparent for lung function in men and women with increasing BMl, even after adjustment for age and height.

Strong negative correlations between BMI and basal FVC, $\mathrm{FEV}_{1}$ and PEF values in children were reported by Ülger et al. ${ }^{7}$ However, it was reported by Tantisira et al. ${ }^{16}$ that increases in BMI were associated with increased spirometric pulmonary function in children. BMI was positively associated with spirometric measurements including FEV $1, F V C$, and PEF.

Our results show that the mean difference in PEF between matched $\mathrm{BMI}$ and $\mathrm{BMI} \%$ was significant in early life $(p<0.05)$. PEF was significantly different between non-obese and obese children. After adjustment for age, height, BMI, non-obese and obese $\mathrm{BMI} \%$, the differences in PEF remained statistically significant at $\mathrm{p}<0.05$.

In addition, our data show that there is a significant association between BMI and PEF in all age groups, even in young children. Compared with children with $\mathrm{BMl} \leq 95$ th percentile, PEF values were lower in children in the age range 6-14 years. Castro-Rodriguez et al. ${ }^{17}$ found that girls who became overweight between 6 and 11 years of age were 5.5-7 times more likely to develop new asthma symptoms at the age of 11-13 years than girls who did not become overweight or obese between the ages of 6 and 11. On its own, the ageadjusted regression model showed that BMI was inversely related to respiratory function in both boys and girls, as also reported by Canoy et al..$^{5}$

The study shows that PEF is lower in obese children. PEF is considered to be an objective measure of airflow resistance in the lungs, which means that there is an increase in respiratory resistance with obesity. It is likely that the association of higher BMI with lower PEF may indicate that obesity is an important risk factor for reduced airflow or lung function. The reduction in the prevalence of childhood asthma could be related to improved patient awareness and prevention of obesity.

\section{Handling editor \\ Chris Griffiths}

\section{Statistical review}

Gopal Netuveli

\section{Conflicts of interest}

The authors declare that they have no conflicts of interest in relation to this article.

\section{Contributorship}

We would like to thank Assoc. Prof. O Gundogdu for his invaluable help and advice.

\section{Funding}

No external funding has been used.

\section{References}

1. He Q, Ding YZ, Fong D Yee-Tak, Karlberg J. Blood pressure is associated with body mass index in both normal and obese children. Hypertension 2000;36:165-70.

2. www.cdc.gov/nccdphp/dnpa/obesity/.

3. Ylikahri M, Mustajoki P, Stenius-Aarniala B, Poussa T, Kvarnström J, Grönlund E-L. Immediate and long term effects of weight reduction in obese people with asthma: randomised controlled study. BMJ 2000;320:827-32. http://dx.doi.org/ 10.1136/bmj.320.7238.827

4. Li AM, Chan D, Wong E, Yin J, Nelson EAS, Fok TF. The effects of obesity on pulmonary function. Arch Dis Child 2003;88:361-3. http://dx.doi.org/ 10.1136/adc.88.4.361

5. Canoy D, Luben R, Welch A, et al. Abdominal obesity and respiratory function in men and women in the EPIC-Norfolk Study, United Kingdom. Am J Epidemiol 2004;159:1140-9. http://dx.doi.org/10.1093/aje/kwh155

6. Rasslan Z, Saad R, Stirbulov R, Fabbri RMA, Da Conceição limae CA. Valuation of pulmonary function in class I and II obesity. J Bras Pneumol 2004;30:508-14.

7. Ülger Z, Demir $E$, Tanaç $R$, et al. The effect of childhood obesity on respiratory function tests and airway hyperresponsiveness. Turkish J Pediatr 2006;48:43-50.

8. A Pocket Guide for Physicians and Nurses based on the workshop report: global strategy for asthma management and prevention (updated 2005).

9. Brand PLP, Roorda RJ. Usefulness of monitoring lung function in asthma. Arch Dis Child 2003;88:1021-5. http://dx.doi.org/10.1136/adc.88.11.1021

10. Sly PD, Flack F. Is home monitoring of lung function worthwhile for children with asthma? Thorax 2001;56:164-5. http://dx.doi.org/10.1136/thorax.56.3.164

11. Frontini MG, Bao W, Elkasabany A, Srinivasan SR, Berenson G. Comparison of weight-for-height indices as a measure of adiposity and cardiovascular risk from childhood to young adulthood: The Bogalusa Heart Study. I Clin Epidemiol 2001;54:817-22. http://dx.doi.org/10.1016/S0895-4356(01)00343-2

12. De Lorenzo A, Maiolo C, Mohamed El, Andreoli A, De Luca PP, Rossi P. Body composition analysis and changes in airways function in obese adults after hypocaloric diet. Chest 2001;119:1409-15. http://dx.doi.org/10.1378/ chest.119.5.1409

13. Bundak R, Furman A, Gunoz H, Darendeliler F, Bas F, Neyzi O. Body mass index references for Turkish children. Acta Pædiatr 2006;95:194-8. http://dx.doi.org/ 10.1080/08035250500334738

14. Poulain M, Doucet M, Major GC, et al. The effect of obesity on chronic respiratory diseases: pathophysiology and therapeutic strategies. CMAJ 2006;174:1293-8. http://dx.doi.org/10.1503/cmaj.051299

15. Lazarus R, Gore CJ, Booth M, Owen N. Effects of body composition and fat distribution on pulmonary function in adults. Am J Clin Nutr 1998;68:35-41.

16. Tantisira KG, Litonjua AA, Weiss ST, Fuhlbrigge AL. Association of body mass with pulmonary function in the Childhood Asthma Management Program (CAMP). Thorax 2003;58:1036-41. http://dx.doi.org/10.1136/thorax.58.12.1036

17. Castro-Rodríguez JA, Holberg CJ, Morgan WJ, Wright AL, Martinez FD. Increased incidence of asthmalike symptoms in girls who become overweight or obese during the school years. Am J Respir Crit Care Med 2001;163:1344-9.

Available online at http://www.thepcrj.org 